\title{
Bakım Uygulamalarında Robotların Yardımcı Ekipman Olarak Kullanılması
}

\author{
Sezcan Yılmaz
}

\section{ÖZ}

Periyodik bakım ve arıza/hasar tespiti genellikle bakım personeli tarafindan manuel olarak gerçekleştirilmektedir. Arızanın tespiti için sadece gözlemin yeterli olduğu bazı durumlar olmasına rağmen genellikle ölçüme de ihtiyaç duyulmaktadır. Diğer taraftan arızanın giderilmesi için de birçok durumda yine bakım personelinin doğrudan müdahalesine ihtiyaç duyulmaktadır. Bakım personelinin gerçekleştirdiği faaliyetlerin tümünün robotlara devredilmesi günümüz teknolojisinde henüz mümkün değildir. Bu nedenle günümüzde bakım, arıza tespiti ve onarımda kullanılan robotlar daha çok bakım personellerine yardımcı ekipmanlar olarak görülmektedir. Her türlü bakım ihtiyacı için kullanılabilecek tek bir robot olmadığından, birçok uygulama görev tabanlı robotları gerektirir. Bu çalışmada robotik bakım uygulamaları ve sağladığı avantajlar değerlendirilmiştir.

Anahtar Kelimeler: Bakım, mobil robot, robotik kol, artık robot, kablo sürücülü robot, haptik

\section{Using Robots as Auxiliary Equipment in Maintenance Applications}

\begin{abstract}
Periodic maintenance and malfunction/damage detection are usually carried out manually, by maintenance personnel. Although there are some situations where simple observations are sufficient for fault detections, measuring instruments are generally needed. On the other hand, direct intervention of maintenance personnel is also required in many cases to eliminate malfunctions. Because of the fact that it is not yet possible in today's technology to transfer all the activities performed by the maintenance personnel to the robots, the robots used in maintenance, fault detection and repair are seen as auxiliary equipment for maintenance personnel. As there is no one robot useable for all sorts of maintenance needs, many applications call for task-based robots. In this study, applications and benefits of robotic maintenance are evaluated.
\end{abstract}

Keywords: Maintenance, mobile robot, robotic arm, redundant robot, cable driven robot, haptic

\footnotetext{
Geliş/Received $\quad: 24.03 .2020$

Kabul/Accepted : $\quad 18.06 .2020$

* Dr. Öğr. Üyesi, Eskişehir Osmangazi Üniversitesi, Makine Mühendisliği Bölümü - sezcan@gmail.com ORCID: 0000-0001-9329-5423
} 


\section{GíRiş}

Üretimde robot kullanımı sıklıkla karşılan bir durumken bakım faaliyetlerinde robot kullanımı oldukça kısıtlıdır. Bu durumu sadece maliyetle açılamak mümkün değildir. Arıza tespiti ve onarımı uygulamalarında birbirinin aynı arızalı cihazlar için bile bulundukları ortama göre farklı iş akışları gerekebilir. Üretim faaliyetlerinde iş akışı önceden bilindiğinden robot kullanımı ile işin otom hale getirilmesi mümkündür. Robot kullanımı üretim hızının artmasına ve hataların azalmasına yardımcı olmaktadır. Ancak arıza tespiti ve onarım süreci için üretimdeki kadar açık ve önceden bilinen bir iş akışı hazırlamak oldukça güçtür. Bu nedenle bakım faaliyetlerinde kullanılan robotlar genellikle bakım personelinin boyutları, bulunduğu yer veya güvenlik gerekçesiyle ulaşmasının zor olduğu veya mümkün olmadığı ortamlarda gerçekleştirilecek olan görsel muayene ve onarımlarda karşımıza çıkmaktadır.

Günümüzde bakım alanında kullanılan robotların büyük bölümü arıza tespitinde kullanılmaktadır. Arızanın tespitinden sonra tamir işlemi mümkünse robotla değilse doğrudan bakım personeli tarafından gerçekleştirilir. Arızalı bölgenin bakım personelinin doğrudan ulaşamayacağı bir bölgede olması durumunda, arızalı bölgeye ulaşmak için birçok ekipmanın sökülmesini ve tamirat sonrasında yeniden montajlanması gerekir. $\mathrm{Bu}$ gibi durumlarda arızanın robotik ekipmanlar vasıtasıyla dışarıdan giderilebilmesi işlem zamanından büyük bir kazanım sağlayacaktır.

Bakım uygulamalarında çok çeşitli tip (mobil, kol tipi ve kablo sürücülü) ve boyutlarda robotlar kullanılmaktadır. Ancak bakım uygulamalarında kullanılan robotları gruplamak oldukça zordur. Görev esaslı olarak yapılandırılan bakım robotları üzerinde kol bulunan bir mobil platform [1] olabileceği gibi ucuna yılan benzeri bir mekanizma takılarak gereğinden çok serbestlik dereceli bir yapı haline getirilmiş olan bir robotik kol [2] şeklinde de olabilir. Buradan da anlaşılacağı üzere bakım robotları ihtiyaçlara cevap verecek şekilde çok farklı konfigürasyonlarda oluşturulabilmektedir.

Robot tiplerinden hangisinin üzerinde hangi ekipmanla kullanılması gerektiği gerçekleştirilecek bakım faaliyetine bağımlıdır. Bu nedenle öncelikle bakım faaliyetinin gereksinimleri tam olarak belirlenmeli ve bu gereksinimler doğrultusunda robot tipi seçilmelidir. Örneğin çok dar bir kapalı alanda hava robotunun kullanılması uygun değilken bir uçağın üst gövdesinin uçuş sonrası muayenesinde de kara robotu yerine hava robotu kullanmak çok daha etkin bir çözüm olacaktır.

$\mathrm{Bu}$ çalışmada robotların bakım alanında yardımcı ekipman olarak kullanılması halinde getirebileceği faydalar sunulurken aynı zamanda da bu ekipmanların kullanılabilirliklerinin şartları ortaya konulmaya çalışılmıştır. Robotik ekipmanlar mobil robotlar ve robotik kollar şeklinde iki ana başlık altında incelenmiştir. 


\section{MOBIL ROBOTLAR}

Mobil robotların bakım faaliyetlerinde kullanım amaçları, üzerlerinde bulundurdukları ekipmana bağlı olarak değişiklik göstermektedir. Üzerlerinde robotik kol bulundurmayıp sadece ölçüm ya da görüntüleme ekipmanı bulunduran mobil platformalar onarımdan ziyade araştırılan bölgede bir aksaklığın olup olmadığının tespiti için kullanılmaktadırlar. Mobil robotların onarım faaliyetinde kullanılabilir olması için üzerlerinde robotik kol bulunduruyor olmaları önemlidir.

Mobil robotlar kara, hava ve/veya suda gidebilecek şekilde üretilmektedir. Bakım onarım faaliyetinin gerçekleştirileceği ortama ve göreve göre hangi mobil platformun kullanılacağına karar verilir. Kara ortamında büyük bir alanın kısa sürede incelenmesi gerekiyorsa ve ortamda buna müsaitse kara robotları yerine çok rotorlu insansız hava araçları (İHA) daha uygun bir çözüm olacaktır. Ancak çok rotorlu İHA’ların tek şarjla gerçekleştirebilecekleri görevin süresi oldukça kısıtlıdır. Bu nedenle uzun süreli ayrıntılı inceleme gerektiren uygulamalarda bu durum dikkate alınmalıdır. Görev süresi uzadıkça sürekli batarya değişimi gerekliliği ortaya çıkacağından en uygun çözüm olma durumu değişebilir.

Günümüzde robotların bakım faaliyetlerinde yardımcı ekipman olarak en çok kullanıldıkları yerlerden birisi havacılık sektörüdür. Havacılık alanında faaliyet gösteren bakım şirketleri muayene ve onarım faaliyetlerini hızlandırmak için robotik çözümlerden yararlanmaktadır [3]. Örneğin büyük gövdeli yolcu veya kargo uçaklarının görev dönüşü dış gövdelerinde ezik, yırtık veya yanık [4] gibi herhangi bir hasar olup olmadığının görsel olarak incelenmesi gerekir. Alt gövdenin görsel incelemesi genellikle kolaylıkla yapılabilir ancak üst gövdenin gözle incelenmesi için geleneksel yöntemde sepetli vinçe içerisindeki bakım personeline ihtiyaç duyulmaktadır ve hiçte pratik değildir. Örneğin kış koşullarında personelin 12 metrelik bir platformda güvende tutmak oldukça zordur. Hatta sepetli vinçin kendisinin dahi ek bir hasar oluşturma potansiyeli vardır [4]. Ancak günümüzde üst gövdenin görsel muayenesinde Şekil 1'de görüldüğü üzere üzerinde yüksek çözünürlüklü kameralar bulunan döner kanatlı insansız hava araçları (İHA) kullanılabilmektedir. Bu sayede muayene faaliyeti herhangi bir yerde herhangi bir zamanda kolaylıkla gerçekleştirilebilmektedir. Ancak bu işlemlerin gerçekleştirilmesinde önceden bir prosedür tanımlanmalıdır. Bu araçların yakıt deposu kapaklarına ve uçağın hava alıklarına belirli bir mesafeden fazla yaklaşmaması güvenlik açısından önemlidir. Ayrıca görsel muayenenin gerçek zamanlı ve verimli bir şekilde gerçekleştirilebilmesi için kablosuz olarak yüksek veri aktarım hızına ihtiyaç duyulmaktadır. İHA'nın konumlandırılmasında en az 10-15 cm hassasiyete ihtiyaç duyulmaktadır [4]. Bu hassas konumlandırma içinde özel yazılım ve ekipmanlar kullanılmalıdır.

$\mathrm{Bu}$ yöntem sadece uçaklarda değil insan sağlığı açısından sakıncalı olan radyoaktif, kimyasal veya biyolojik olarak kirlenmiş ortamlarda gerçekleştirilen bakım faaliyet- 


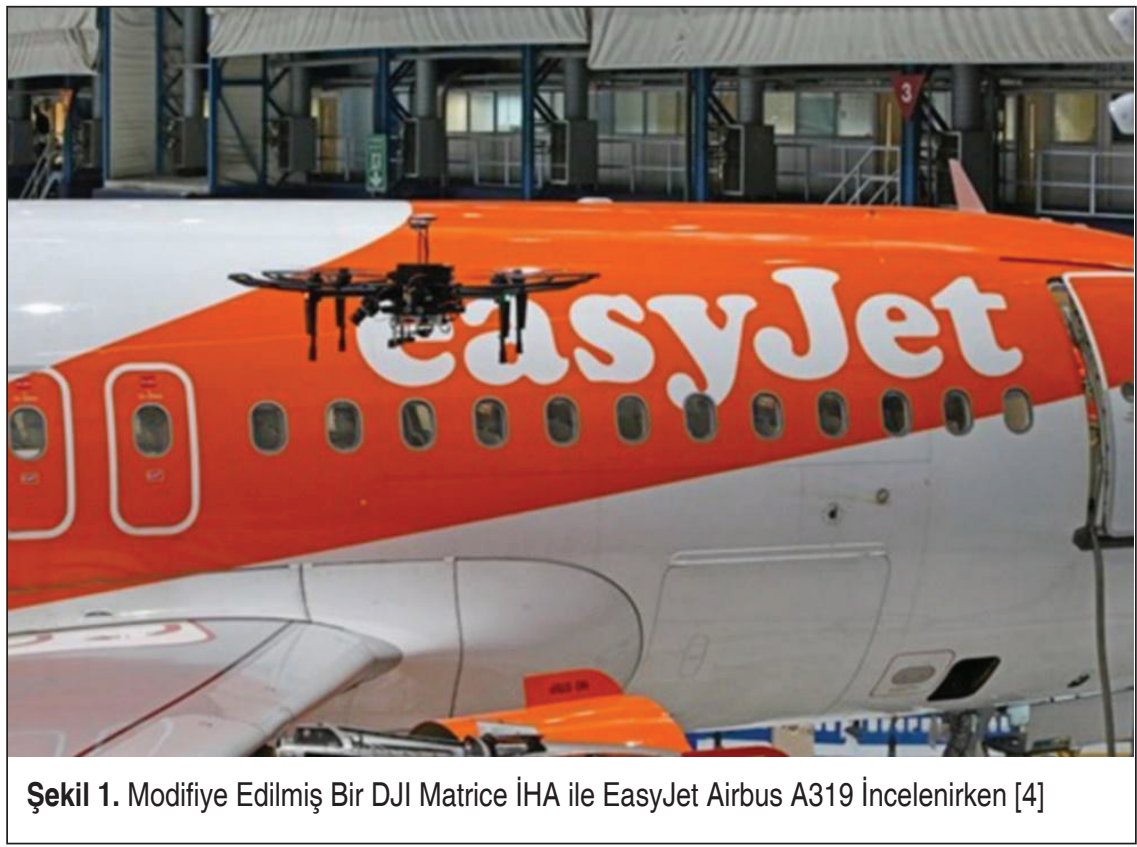

lerinde da kullanılabilir. Bu sayede riskli bölgenin görsel muayenesi için operatör göndermek gibi ilave risklerde alınmamış olur. Döner kanatlı İHA'ların en büyük k1sıtları ise taşıma kapasitelerinin çok kısıtlı olmasının yanında üzerlerine ilave edilen her ekipmanla birlikte artan ağırlıkları dolasıyla tam dolu batarya ile gerçekleştirecekleri toplam uçuş sürelerinin çarpıcı bir şekilde düşmesidir. Bir diğer sakıncası ise dar alanlarda kullanımlarının oldukça zor olmasıdır.

$\mathrm{Su}$ altı robotlarının kullanım alanları ise gemi tabanlarından su altı yapılarının görsel muayene ve basit onarımlarına kadar farklı alanları kapsamaktadır. İHA'larından farklı olarak ekstra ekipman taşıma kabiliyetleri oldukça yüksektir ve üzerlerinde robotik kollar barındırabilirler. Bu sayede hem muayene hem de onarım işlemlerinde kullanılabilirler. Özellikle derin sularda kullanılacak olan robotların ve üzerlerinde bulunduracakları ekipmanların yüksek basınç dayanımlarının iyi olması gereklidir. Sığ sularda sadece görsel muayene için kullanılan robotlar çok küçük boyutlu iken derin sularda kullanılan hem görsel muayene hem de onarım ekipmanları barındıran robotlar ise oldukça büyük boyutludur. Yine İHA'lardan farklı olarak batarya ile kullanılmaları gibi bir zorunlulukları olmayıp enerjilerini elektrik iletim hatları ile dış bir kaynaktan alabildiklerinden kesintisiz olarak oldukça uzun süreler kullanılabilirler.

Kara robotlarını tekerlekli, paletli, ayaklı ve sürünerek ilerleyenler şeklinde gruplamak mümkündür. Tekerlekli ve paletli robotların aynı boyutlu ayaklı ya da sürünerek ilerleyen robotlara nazaran yük taşıma kabiliyetleri yüksekken güç tüketimleri ise ol- 
dukça düşüktür. Kara robotları batarya ile veya dış enerji kaynakları ile kullanılabilirler. Enerji kaynağı tercihi kullanılacakları ortama göre belirlenmektedir. Boyutlarına göre üzerlerinde taşıyabilecekleri ekipman miktarı oldukça değişiklik göstermektedir. Şekil 2'de mobil robot platformlarından iki tanesi görülmektedir. Şekil 2(a)'da görülmekte olan Mitsubishi MEISTeR (Maintenance Equipment Integrated System of Telecontrol Robot) nükleer sahalarda kullanılmak üzere geliştirilmiş ve özellikle Fukushima Daiichi Nükleer Güç Santrallerinde çalışabilecek şekilde üretilmiştir [5]. MEISTeR mobil platformunun kol gibi de hareket edebilen paletleri bulunmaktadir. $\mathrm{Bu}$ sayede engebeli sahalarda da hareket edebilmektedir. Şekil 2(b)'de görülmekte olan KUKA KMR QUANTEC mecanum tekerlekli bir platform olup düz zeminlerde oldukça hassas ve sınırsız bir manevra kabiliyetine sahiptir [6]. Üzerine takılan robotik kolu çok hassas bir biçimde konumlandırabilen bu sistem sayesinde büyük ve hassas parçalar (uçak gövdesi, rüzgar türbini kanadı vb.) üzerinde işlem (boya sökme, boyama, onarım vb.) yapmakta yararlanılmaktadır.

Robotların bakım faaliyetlerinde kullanıldığı diğer bir sektör ise boru hatları ve sıv1 depolama sistemleridir. Bazı robotlar manyetik tekerlekleri sayesinde uygun yüzeylerde düşey yönde dahi hareket edebilmektedir. Şekil 3'te GE Inspection Robotics firmasının BIKE Platform [7] ve FAST RVI [8] modelleri görülmektedir. Bu robotlar boru hatları ve depolama tanklarının görsel muayenesi için özel olarak üretilmiş olup sıklıkla kullanılmaktadır.

Sadece boru hatlarında kullanılabilen çok farklı tip [9] ve boyutta kara robotları vardır. Bunlardan bazıları Şekil 4(a)'da görülmekte olan Inuktun Services Ltd.'nin VT100 Vertical Crawler ${ }^{\mathrm{TM}}$ robotunda olduğu gibi farklı çapladaki borulara göre boyutu ayarlanabilecek ve tek boyutlu harekete uygun olacak şekilde tasarlanmışlardır [10]. Diğer bazıları ise Şekil 4(b)'de görüldüğü gibi gaz dağıtım hatları gibi kollara ayrılabilen boru hatlarında bir koldan istenilen bir diğerine geçebilecek şekilde çok boyutlu harekete uygun olarak tasarlanmışlardır [11].

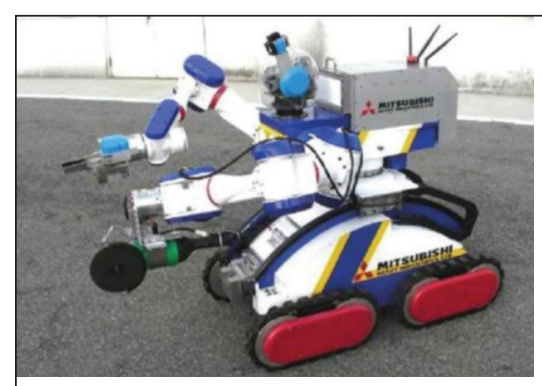

(a) Mitsubishi MEISTeR [5]

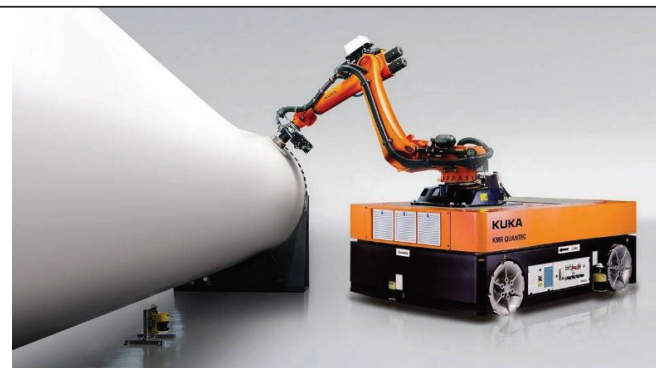

(b) KUKA KMR QUANTEC [6]

Şekil 2. Karada Gidebilen Mobil Robot Platformları 


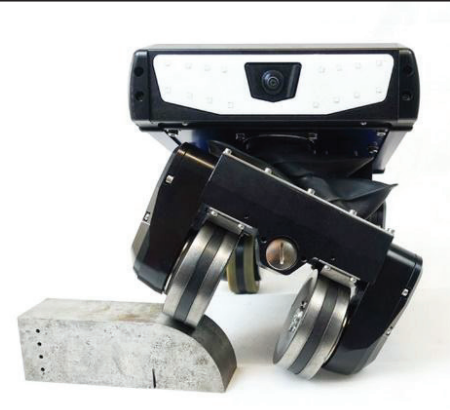

(a) GE Inspection Robotics BIKE Platform [7]

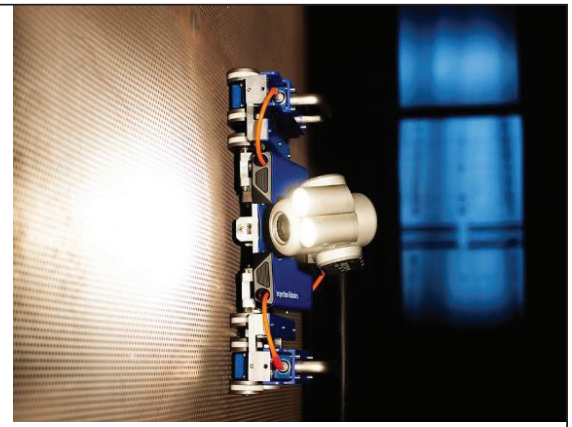

(b) GE Inspection Robotics FAST RVI [8]

Şekil 3. Metal Cidarlı Boru Hatları ve Sıvı Depolama Sistemlerinde Kullanılan Mobil Robotlar

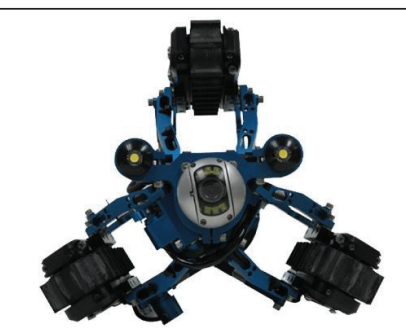

(a) VT100 Vertical Crawler [10]

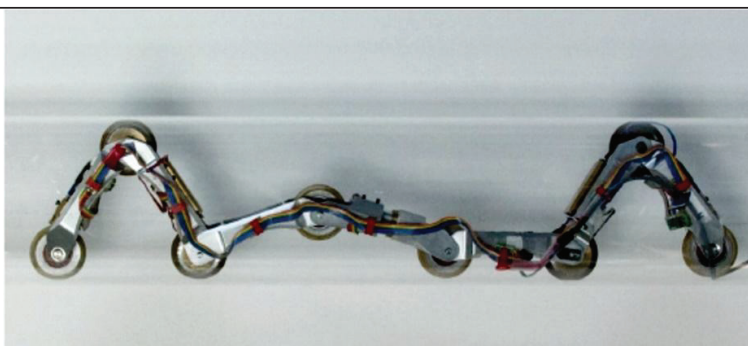

(b) Minyatür boru muayene robotu [11]

Şekil 4. Silindirik Boru Hatları İ̧in Özel Olarak Geliştirlmiş Mobil Robotlar

Günümüzde tekerlekli ve paletli robotların kullanımları daha yaygın olmasına karşın bu robotların hareket etmesinin mümkün olmadığı ortamlarda yılanlardan ilham alınarak geliştirilmiş olan sürünerek ilerleyen robotların kullanımı düşünülebilir. Ancak sürünebilen robotlar yapıları gereği kısıtlı boyut ve miktarda ilave ekipman taşıyabilirler.

Sonuç olarak mobil robotlar bakım faaliyetlerinde onarımdan ziyade gözlem, ölçüm ve onarım ekipmanlarının ilgili yere iletilmesi için kullanılmaktadırlar. Onarımın gerçekleştirilmesi için yardımcı ekipman olarak genellikle robotik kollara ihtiyaç duyulmaktadır. 


\section{ROBOTIK KOLLAR}

Robotik kollar montajdan paketlemeye kadar üretimin tüm aşamalarında sıklıkla kullanılan yapılardır. Seri, paralel veya hibrit kinematik yapılara sahip olabilirler. Bakım faaliyetlerinde kullanılmakta olan robotik kollarda sistemin serbestlik derecesi büyük bir önem arz etmektedir. Altı serbestlik dereceli bir robotik kolun son eğleyicisi ile teorik olarak çalışma uzayı içerisinde yer alan herhangi bir noktaya istenilen yönelimle ulaşılabilir. Ancak pratik uygulamalarda çalışma uzayı içerisinde herhangi bir engel yer alması halinde robot uzuvlarının kinematik kısıtları dolayısıyla çalışma uzayının ulaşılabilir büyüklüğü engelin hacminden çok daha fazla kısıtlanacaktır. Bu gibi durumlarda çalışma uzayının ulaşılabilir büyüklüğünün olabildiğince arttırılabilmesi için robotik kol ilave serbestlik derecesine ihtiyaç duyar. Kinematik olarak uygun şekilde ilave edilen her serbestlik derecesi ile birlikte çalışma uzayının ulaşılabilir büyüklügü de artacaktır. Çalışma uzayında bulunan engellerden kaynaklı kısıtların aşılması için serbestlik ilave edilen robotik kollara gereğinden fazla serbestlik dereceli yapılar ismi verilmektedir.

Bakım faaliyetlerinde kullanılan robotik kollar sabit kaideli, taşınabilen kaideli ve mobil robot platformları üzerine konuşlandırılmış olarak kullanılabilmektedir. Sabit kaideli robot kollar daha çok bakım yapılmak üzere sökülen makine parçalarının atölye şartlarında onarılmaları için kullanılmaktadır. Bakım faaliyetlerinde sabit kaideli olarak kullanılmakta olan robotik kollar genellikle altıdan daha düşük serbestlik derecesine sahiptir. Taşınabilen kaideli robot kollar ise bakım yapılacak bölgeye götürülerek muayene, revize veya onarım yapılacak makine parçaları yerinden sökülmeden işlem gerçekleştirilir. Taşınabile kaideli robotik kollardan bazıları hareketli sehpalara montajlı olarak kullanılmaktadır. Diğer bazıları ise Şekil 5'te görülmekte olan Lufthansa Technik (LHT) tarafından geliştirilen CAIRE (Composite Adaptable Inspection and Repair) sisteminde olduğu gibi uçak kanatlarında ve gövdesindeki karbon fiber takviyeli polimerlerin yerinde onarımını yapmak üzere doğrudan bakımı gerçekleştirilecek sistemin gövdesine sabitlenerek kullanılmaktadır [3]. Robotik kolların mobil robotların üzerine konuşlandırılmalarının en önemli sebeplerinden birisi operatörlerin bakım faaliyetinin gerçekleştirileceği bölgeye güvenlik ve/veya fiziki sebeplerden dolayı ulaşamamalarıdır.

Endüstriyel faaliyetlerde oldukça yaygın olarak kullanılmakta olan seri kinematik yapılı robotik kollarda aktüatörler genellikle eklemlerde konumlandırılmaktadır. Aktuatörlerin eklemlerde yer alıyor olması fiziki boyutları ve mukavemet kısıtlarından dolayı robotik kolu kesit/uzunluk oranı büyük olan bir fiziki yapıya zorlamaktadır. Engellerin çok olduğu kısıtlı bölgelerde gerçekleştirilmekte olan bakım faaliyetlerinde böyle bir robotla işlem gerçekleştirmek oldukça güçtür. Bu problemin üstesinden gelmekte kablo sürücülü mekanizmalar oldukça uygun çözümler üretmektedir. Doğrudan sürülen mekanizmalara nazaran tek eklemde elde edilebilecek hareket aralığ 1 


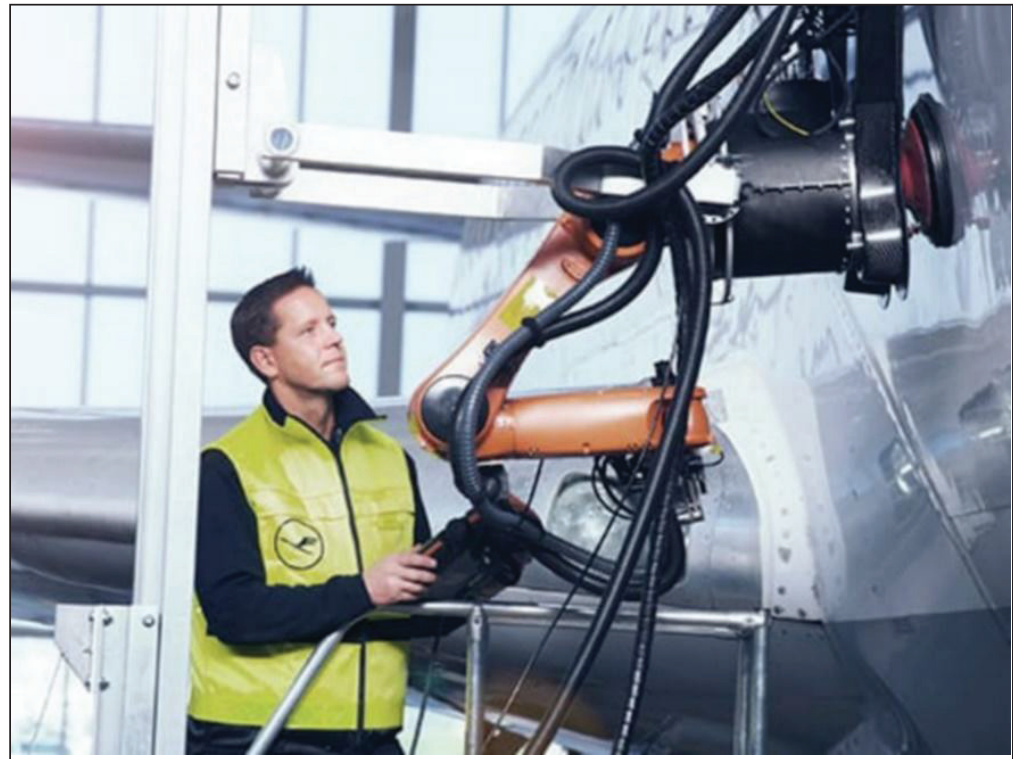

Şekil 5. LHT'nin CAIRE Robotu [3]

oldukça kısıtlı ve hassasiyetleri düşüktür. Buna rağmen aktüatörlerinin kolun üzerinde yer almıyor olması sayesinde, bu yöntemle gereğinden çok serbestlik dereceli bir yapıyı oldukça küçük bir kesit/boy oranıyla elde etmek mümkün olabilmektedir. Bu yapılar aynı zamanda artık robot veya yılan benzeri robotik kol şeklinde de isimlendirilmektedir. Yılan benzeri robotik kollar kendi başlarına kullanılabilecekleri gibi

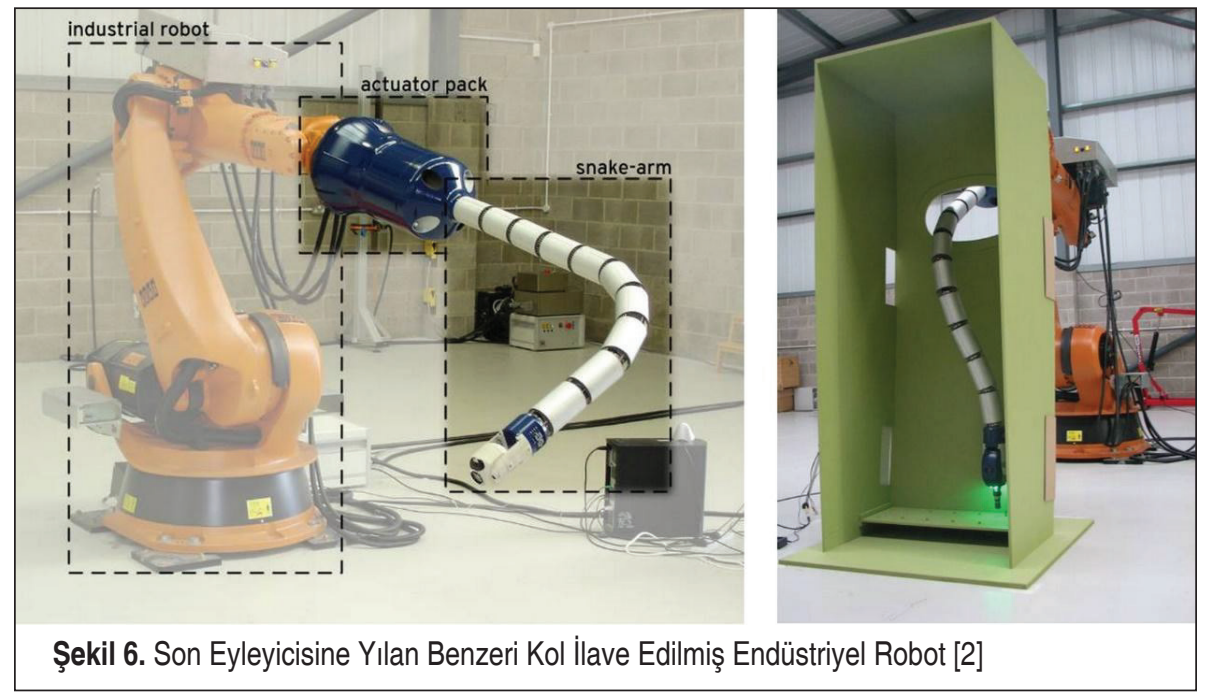


bir endüstriyel robotun son eyleyicisine [2] veya bir mobil robot platformuna [12,13] montajlanarak ta kullanılabilirler. Şekil 6'da OC Robotics ve Airbus tarafından geliştirilen yılan benzeri bir robotik kolun KUKA endüstriyel robotunun son eğleyicisine monte edilmiş hali görülmektedir [2].

Pratik kullanıma dönük olarak geliştirilmekte olan birçok yılan benzeri robotik kol bulunmaktadır. Aynı zamanda bu yapıların hareket kabiliyetlerinin geliştirilmesi, katılık değerlerinin yükseltilmesi ve hassasiyetlerinin iyileştirilmesi önemli araştırma alanları arasındadır. Yılan benzeri robotik kollar küresel mafsallı ve esnek uzuvlu olarak üretilebilmektedir [14]. Mafsal yerine esnek uzuv kullanılması mekanizmaya teorik olarak sonsuz sayıda mafsala sahipmiş gibi çok daha esnek bir şekilde hareket edebilme kabiliyetinin yanında boyutlarının da çok daha küçültülmesine imkan tanımaktadır [14,15]. Şekil 7'de gösterilen yılan benzeri mekanizmanın çapı 0.8 ile 2.5 $\mathrm{mm}$ arasında bir değere getirilmiştir [15]. Bu sayede çok daha dar alanlara ulaşılarak muayene gerçekleştirmek mümkün olmaktadır.

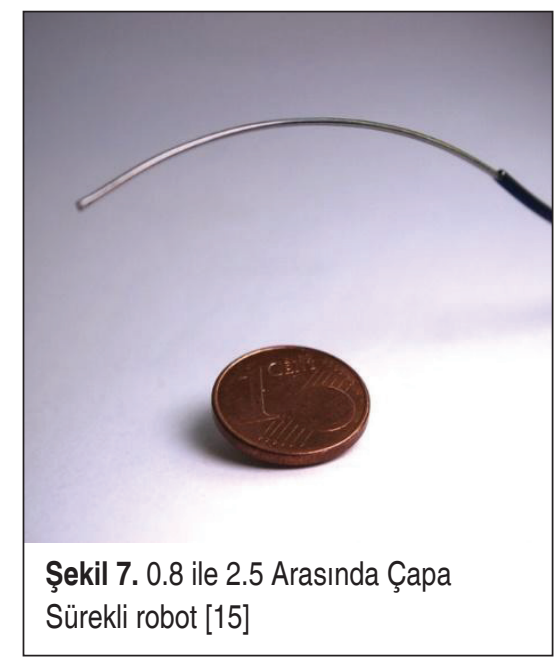

\section{OPERATÖR TERMINALLERİ}

Bakım robotlarının etkinliğini belirleyen en önemli faktörlerden biriside operatörler tarafından robotların yönlendirilmesinde kullanılan kontrol ekipmanlarıdır. Burada operatörün tecrübesi kadar yönlendirmede kullanılan kontrol ünitesinin kabiliyetleri de önem arz etmektedir. Kontrol ünitelerinin mobilite, egronomi, hassasiyet, bant genişliği ve tepki süresi gibi birçok özelliği bulunmasının yanında operatörün robotu yönlendirmek için kullanacağı yöntemde büyük bir önem arz etmektedir. Bazı uygulamalarda klavye üzerinden veya basit bir joystick yönlendirme için yeterli olmak- 
ta iken bazı uygulamalarda dokunsal ekranlı el terminalleri üzerinden yönlendirme çok daha kolaylık sağlamaktadır. Klavye, basit bir joystick veya dokunsal ekranlar üzerinden gerçekleştirilen kontrolde operatör robotu genellikle sadece görsel bir geri bildirimle yönlendirmek durumunda kalmaktadır ve birçok uygulama için bu oldukça yeterli ve ekonomik bir çözüm olarak karşımıza çıkmaktadır. Ancak daha hassas veya karmaşık sistemlerde robotların yönlendirilmesinde operatörün robotla sadece görsel bir etkileşim içerisinde olması yeterli olamamakta ve bunun yanında haptik etkileşime de ihtiyaç duyulmaktadır. Haptik etkileşim operatöre görsel etkileşime ilave olarak robotla dokunsal ve kinestetik algı yoluyla etkileşimde bulunma olanağı sunmaktadır. Kinestetik algı kaslar, tendonlar ve eklemlerde bulunan sinir hücreleri vasıtasıyla insan uzuvlarının konum, hareket ve dış kuvvet etkilerinin hissedilmesi olarak tanımlanabilir. Dokunsal algı deride bulunan reseptörler vasıtası ile deriye uygulanan basıncın hissedilmesidir. Haptik cihazlar sayesinde ameliyat uygulamalarında [16] dahi kullanılabilecek hassasiyette kontrol mümkün olmaktadır. Özellikle kinestetik algıya hitap eden heptik cihazlar [17] yapısal olarak kütlesel atalet momenti değerleri çok düşük paralel veya seri robotik kollardan ibarettir. Ancak haptik cihazlar diğer yöntemlere nazaran kontrol ünitesinin fiziksel ve yazılım maliyetlerini arttırmaktadır. Bu nedenle bu tip kontrol ekipmanları genellikle hassas işler için tercih edilmektedir. Mobil robotların veya robotik kolların yönlendirilmesinde nasıl bir ekipmanla gerçekleştirileceği görevin ihtiyaçları doğrultusunda belirlenmektedir.

\section{SONUÇLAR}

$\mathrm{Bu}$ çalışmada bakım esnasında muayene ve onarım işlemlerinde yardımcı ekipman olarak kullanılmakta olan robotik yapılar incelenmiştir. Robotik yapıların kullanılmaları ile ilgili örnek uygulamalara değinilerek üstün ve eksik yönleri vurgulanmıştır. $\mathrm{Bu}$ çalışmada robotik yapılar mobil robotlar ve robotik kollar şeklinde iki bölüme ayrılarak incelenmesine rağmen verilen örneklerden de görüleceği üzere pratikte bu robotik yapılar çoğunlukla bir arada kullanılmaktadır. Mobil robotlar kendi başlarına genellikle sadece muayene işlemde kullanılabilmektedir. Eğer bakım faaliyeti bir onarım işlemini de kapsıyorsa robotik kol gereksinimi neredeyse kaçınılmazdır.

Bakım faaliyetinde nasıl bir robotun kullanılması gerektiğine karar vermek için ortamın fiziki durumu oldukça önem arz etmektedir. Özellikle ortamın boyutları ve içeride bulunan engeller önemlidir. Ortam ne kadar daralırsa işlemin gerçekleştirilmesinde kullanılabilecek robot alternatifleri de o oranda azalmaktadır.

Endüstriyel robotlar bakım faaliyetlerinde sıklıkla kullanılmaktadır. Ancak bu robotlar kendi başlarına kullanıldıklarında yapı içerisindeki engellerden kaynaklı olarak çalışma uzayları içerisindeki her noktaya ulaşamazlar ve hareketleri büyük ölçüde kısıtlanır. Bu durumun bertaraf edilebilmesi için gereğinden fazla serbestlik dereceli robotik kollar ya da yılan benzeri robotik kollar kullanılmalıdır. 
Bu çalışmada görüldüğü üzere birçok bakım uygulamasına yönelik robotik yapı mevcuttur. Genellikle göreve özel tasarlanan bu robotlar bazı konularda çok mahirdirler. Her geçen gün yeni gelişmeler yaşanmasına rağmen robotlar halen birçok alanda bakım personeli kadar esnek olmadıkları gibi birçok uygulamada otonom kontrol yerine operatör kontrolüne ihtiyaç duymaktadırlar. Bakımda kullanılan robotların otonom olarak gerçekleştirebildikleri işlemlerin arttırılması, çalışılması gereken araştırma alanlarındandır.

\section{TEŞEKKÜR}

Bu çalışma için bana fikir veren 1'inci Hava İkmal Bakım Merkezi Komutanlığın'dan değerli dostum Makine Yüksek Mühendisi Cihan ALTUN’a teşekkür ederim.

\section{KAYNAKÇA}

1. Sharma, S., Kraetzschmar, G.K., Scheurer, C., Bischoff, R. 2012. "Unified closed form inverse kinematics for the KUKA youBot," ROBOTIK 2012; 7th German Conference on Robotics, May 21-22, 2012, Munich, Germany.

2. Buckingham, R., Chitrakaran, V., Conkie, R., Ferguson, G., Graham, A., Lazell, A., Lichon, M., Parry, N., Pollard, F., Kayani, A., Redman, M., Summers, M., Green, B. 2007. "Snake-arm robots: a new approach to aircraft assembly," SAE Technical Paper (No. 2007-01-3870), SAE Imternational.

3. Read, B. 2019. "Flying, clinging and crawling - using robots in MRO," https://www. aerosociety.com/news/flying-clinging-and-crawling-using-robots-in-mro/, son erişim tarihi: 23.03 .2020 .

4. Evans, R. 2018. "Inspector Gadget," https://www.aerosociety.com/news/inspector-gadget/, son erişim tarihi: 23.03.2020.

5. Mitsubishi Heavy Industries Ltd. (MHI). 2012. "MHI Develops "MEISTeR” Disaster Recovery Support Robot With 2 Arms Enabling Light-duty Work Tasks," https://www. mhi.com/news/story/12121603.html, son erişim tarihi: 23.03.2020.

6. KUKA Aktiengesellschaft. "KMR QUANTEC," https://www.kuka.com/tr-tr/\%C3\%BCr\%C3\%BCnler-hizmetler/mobilite/mobil-robotlar/kmr-quantec, son erişim tarihi: 23.03.2020.

7. GE Inspection Robotics. 2018. "BIKE Platform, Ultra mobile inspection robot," https:// inspection-robotics.com/wp-content/uploads/2018/11/2018_08_brochure_BIKE_web_ final.pdf, son erişim tarihi: 23.03.2020.

8. GE Inspection Robotics. 2018. "FAST RVI (Robotic Visual Inspection) in confined space,” https://inspection-robotics.com/wp-content/uploads/2018/11/2018_04_brochure_FAST_RVI_web_final.pdf, son erişim tarihi: 23.03.2020.

9. Mills, G.H., Jackson, A.E., Richardson, R.C. 2017. "Advances in the inspection of unpiggable pipelines." Robotics, vol. 6(4), p. 36. 
10. Eddyfi Technologies. "Inuktun VT100 Vertical Crawler ${ }^{\mathrm{TM}}$," https://eddyfi.com/en/product/vt100-vertical-crawler, son erişim tarihi. 23.03.2020.

11. Dertien, E., Stramigioli, S. 2011. "Basic maneuvers for an inspection robot for small diameter gas distribution mains," 2011 IEEE International Conference on Robotics and Automation, May 9-13, 2011, Shangai, China.

12. Fildes, J. 2006. "Snake-arm robots slither forward," http://news.bbc.co.uk/2/hi/technology/5324708.stm, son erişim tarihi: 23.03.2020.

13. Sieger, M. 2017. "A Snake on A Plane: This Long-Arm Robot Will Help Fix Aircraft Engines," https://www.ge.com/reports/snake-plane-longed-arm-robot-will-help-fix-aircraft-engines/, son erişim tarihi. 23.03.2020.

14. Dong, X., Raffles, M., Guzman, S.C., Axinte, D., Kell, J. 2014. "Design and analysis of a family of snake arm robots connected by compliant joints," Mechanism and Machine Theory, vol. 77, p.73-91.

15. Hansen, S. 2017, "Continuum robot offers brand new possibilities," https://aeroreport. de/en/innovation/continuum-robot-offers-brand-new-possibilities, son erişim tarihi: 23.03.2020.

16. Yılmaz, S. 2019. "Haptik Etkileşimin Medikal Uygulamaları," ESOGÜ Bilim Kültür Sanat, sayı 2, s. 35-37.

17. Yılmaz, S., Zafer, N. 2019. "Review of Haptic Devices According to Kinematic Structure," IMSMATEC 2019; The International Conference on Materials Science, Mechanical and Automotive Engineerings and Technology, June 21-23, 2019, Cappadocia, Turkey. 